\title{
O DESAFIO DO ENSINO DA LEITURA NO CONTEXTO CONTEMPORÂNEO
}

\author{
EL DESAFÍO DE LA ENSEÑANZA DE LA LECTURA EN EL CONTEXTO \\ CONTEMPORANEO
}

\section{THE CHALLENGES INVOLVED IN READING PROFICIENCY IN A CONTEMPORARY CONTEXT}

\author{
Claudemir BELINTANE ${ }^{1}$
}

\begin{abstract}
RESUMO: O objetivo do presente trabalho é apresentar alguns resultados de uma pesquisa longitudinal (2011-2014) cujo tema é a alfabetização e o ensino da leitura no Fundamental I, levando em conta o regime de ciclos. A pesquisa estruturou-se em rede (São Paulo, Belém e Pau dos Ferros-RN) e contou com a colaboração de três universidades (USP, UFPA, UERN). Com metodologia de pesquisa-ação, os pesquisadores acompanharam e monitoraram turmas durante quatro anos, intervindo sempre que possível em função dos resultados de avaliações e em consenso com as professoras das escolas. Os resultados revelam: a importância do regime de ciclos e do trabalho coletivo focados no fenômeno da heterogeneidade e das defasagens de nível de leitura ao longo do fluxo; a relevância de um imbricamento bem planejado entre os campos da oralidade, da literatura e da escrita durante o processo, as reconsiderações sobre o funcionamento do regime de ciclos. Os resultados aqui apresentados, apesar de parciais, são importantes para subsidiar políticas em relação ao desafio de alfabetizar e formar leitores proficientes. Dos sessenta alunos acompanhados desde o primeiro ano (2012), mais de setenta por cento mostraram-se leitores proficientes em exigentes testes de leitura tanto dos pesquisadores como do MEC.
\end{abstract}

PALAVRAS-CHAVE: Alfabetização. Leitura. Regime de ciclos.

RESUMEN: El objetivo del presente trabajo es presentar algunos resultados de una investigación longitudinal (2011-2014) cuyo tema es la alfabetización y la enseñanza de la lectura en la educación Fundamental I, teniendo en cuenta el régimen de ciclos. La investigación se estructuró en red (São Paulo, Belém y Pau dos Ferros-RN) y contó con la colaboración de tres universidades (USP, UFPA, UERN). Con metodología de investigación-acción, los investigadores acompañaron y monitorearon grupos durante cuatro años, interviniendo siempre que posible en función de los resultados de evaluaciones y en consenso con las profesoras de las escuelas. Los resultados revelan: la importancia del régimen de ciclos y del trabajo colectivo enfocados en el fenómeno de la heterogeneidad y de los desfases de nivel de lectura a lo largo del flujo; la relevancia de una imbricación bien planeada entre los campos de la oralidad, de la literatura y de la escritura durante el proceso, las reconsideraciones sobre el funcionamiento del régimen de ciclos. Los resultados aquí presentados, aunque sean

${ }^{1}$ Doutor em Educação. Departamento de Educação - Faculdade de Educação, FEUSP/USP, São Paulo, Brasil. E-mail: claubelintane@uol.com.br. 
parciales, son importantes para afirmar políticas en relación a los desafíos de alfabetizar y formar lectores proficientes. De los sesenta alumnos acompañados desde el primer año (2012), más del $70 \%$ se mostraron como lectores proficientes en exigentes testes de lectura tanto de los investigadores como del Ministerio de Educación (MEC).

PALABRAS CLAVE: Alfabetización. Lectura. Régimen de ciclos.

ABSTRACT: The objective of this paper is to present results of a longitudinal research project (2011-2014) on literacy and reading skills of elementary public school children in Brazil. The research focused on the Regime de Ciclos, a curricular organization in which children progress to the next grade level within a 2 or 3-year cycle regardless of their academic achievements or grades, and retention only occurs at the last year the cycle. The research took place in three cities (São Paulo-SP, Belém-PA, and Pau dos Ferros-RN), and included three universities (USP, UFPA, and UERN). Action research was adopted for it allowed to bring school teachers and researchers together to monitor and observe student groups over a four-year period, and to implement different teaching practices based on student assessment. Results show the importance of the Regime de Ciclos alongside with teamwork focused on heterogeneity and on reading achievement discrepancies throughout each cycle. It also reveals the relevance of teaching practices which strongly connect literature, oral and written skills during the process, and the need for constant evaluation of the Regime de Ciclos. Although these are partial results, they are important to substantiate policies that address the challenges of developing literacy proficiency. Seventy percent of the 60 students that were monitored since grade 1 in 2012 demonstrated high levels of reading proficiency in demanding tests administered by the researchers and by the Ministry of Education and Culture.

KEYWORDS: Literacy. Reading proficiency. Regime de ciclos. Heterogeneity.

\section{Introdução}

Apresentamos neste artigo parte do processo e alguns resultados de uma pesquisa longitudinal em rede realizada no período de 2011 a 2014 em três localidades: São Paulo (SP), na Escola de Aplicação da Universidade de São Paulo (EA-FEUSP); Belém (PA), na Escola de Aplicação da Universidade Federal do Pará (EA-UFPA); Escola Municipal Nila Rego, em Pau dos Ferros (RN) em parceria com a Universidade do Estado do Rio Grande do Norte (UERN). Por razões de divisão do trabalho e por ainda não termos efetivado o cruzamento dos dados principais colhidos por vários outros pesquisadores do Projeto, abordaremos exclusivamente o processo e os resultados obtidos no polo de São Paulo, que estão sob responsabilidades deste pesquisador.

O projeto da pesquisa teve como ponto de partida quatro motivações: (1) uma pesquisa anterior realizada em uma escola pública de São Paulo (Projeto FAPESP/2008, 
Belintane (2010)), no qual pretendíamos constatar que, com um manejo didáticopedagógico mais cuidadoso nos anos iniciais, associado a um programa que pusesse em primeiro plano a relação oralidade-escrita e cujo foco não perdesse de vista a heterogeneidade das turmas, poderíamos garantir resultados mais interessantes quanto aos níveis de leitura e de letramento em geral; (2) O edital CAPES/OBEDUC 038/2010, que abria a possibilidade de projetos em rede e por um período suficiente para uma pesquisa longitudinal de longa duração (quatro anos); (3) as parcerias já existentes entre alguns pesquisadores das três universidades que constituem essa rede; (4) da grande dificuldade que se verifica no processo de transposição didático pedagógico no campo da alfabetização e do ensino de Língua Portuguesa, sobretudo quando se consideram resultados efetivos das avaliações oficiais, que parecem contrastar com certo consensos teóricos que vieram ganhado corpo nas três últimas décadas. Como não há espaço para refazer aqui esse percurso, remetemos ao nosso livro, mais precisamente ao capítulo II. O fragmento abaixo resume ainda que parcialmente nossas principais críticas a essa transposição:

Na década de 1990, sob essas influências, estabelecidas na forma de uma síntese meio aberta entre a Análise do Discurso francesa e as obras de Vigostki e Bakhtin e, ainda, em alguns casos, acrescida da concepção construtivista de Ferreiro y Teberosky, formou-se uma concepção que vem prevalecendo discursivamente nas redes de ensino e em praticamente todos as instâncias administrativas dos governos. Nos Parâmetros Curriculares de Língua Portuguesa (PCN-LP) (Brasil, 1998) as ideias de uso-reflexão e de construção do conhecimento, associadas à concepção de gênero de Bakthin, foram assumidas nas instituições oficiais e no mercado de didáticos de uma forma bastante abrangente, não obstante, como mostraremos, de forma bem equivocada, chegando mesmo a contrariar os ideais de suas fontes e de seus divulgadores. (BELINTANE, 2013, p.82).

O novo projeto, intitulado $O$ desafio de ensinar a leitura no contexto do

Fundamental de nove anos (doravante Projeto Desafio), retomou, dentre outras, duas hipóteses integradas que foram parcialmente constatadas no projeto FAPESP/2008, quais sejam: (1) o monitoramento criterioso da heterogeneidade, a partir de uma reorganização do trabalho escolar, pode melhorar significativamente o rendimento das turmas em leitura e, ao mesmo tempo, fornecer dados para uma base curricular que leve rigorosamente em conta o regime de ciclos e suas relações com as singularidades sociais e culturais da escola pública brasileira; (2) a projeção de novos conceitos de oralidade e de infância pode permitir maior inclusão dos alunos que apresentam dificuldades em sua 
entrada na escrita e, ao mesmo tempo, dinamizar a fluência e a apreensão de sentidos na leitura e na produção escrita de quase todos os alunos das turmas de fundamental I.

Essas duas hipóteses foram contempladas em três amplos objetivos, vamos focar apenas o segundo objetivo do projeto, que assim foi formulado: a partir da inserção de pesquisadores no cotidiano das salas de aula das séries iniciais do Ensino Fundamental I (EF-I), nosso objetivo consistia em reunir elementos para um programa de ensino mais adequado à realidade brasileira (diversidade e heterogeneidade), que levasse em conta a possibilidade e as potencialidades de um trabalho em equipe - em outras, a pretensão era e ainda é contribuir para a busca de um modelo de ensino que atribua a grupos de profissionais com formação direcionada para o ensino de língua (Pedagogos, licenciados em Letras/Linguística e outros), responsabilidade ética e capacidade pedagógica para lidar, de forma mais inclusiva possível, com a inserção da criança brasileira no mundo letrado contemporâneo.

A metodologia foi definida como "pesquisa participante", com intervenções no trabalho escolar sempre que as evidências trazidas pela pesquisa e pelas reflexões dos pesquisadores fossem acatadas e assumidas pelas professoras da escola parceira, tal qual preceitua boa parte dos pesquisadores desta área, entre outros: Brandão (1999), Thiolent, (2003) e Schmidt (2006). As educadoras da EA-FEUSP e os pesquisadores estabeleceram desafios comuns - entre outros, dois nucleares: melhorar a performance dos alunos no final dos ciclos do EF-I e traçar as linhas gerais de um novo programa de Língua Portuguesa para os dois ciclos iniciais da escola, levando em consideração o programa anterior que vinha sendo praticado pelas professoras nos últimos anos, mas adequando tudo para assumir os desafios propostos pelo regime de ciclos.

Estrategicamente, inserimos no cotidiano escolar nossos pós-graduandos (mestrandos e doutorandos) e alunos bolsistas de graduação, que além de colher dados, atuavam como professores auxiliares e como produtores de conteúdos para as novas estratégias sob nossa supervisão. Todo o trabalho era (re) organizado em uma reunião semanal de três horas de duração nas quais a participação de todos os envolvidos era obrigatória. Nessas reuniões, sob a coordenação do pesquisador principal, avaliava-se o trabalho da semana, projetavam-se novas estratégias e, sempre que possível, os temas passavam por intensas reflexões e polêmicas. As reuniões eram registradas em atas e socializadas no encontro seguinte, quando recebiam a avaliação dos participantes. No andamento desse processo, produziam-se registros para as pesquisas dos pósgraduandos e, ao mesmo tempo, subsidiavam-se mudanças no programa e discutia-se a 
adequação de cada uma delas ao regime de ciclo. A palavra "desafio" estabeleceu-se nesse cotidiano não apenas como uma meta do projeto, mas também como um compromisso ético de todos para superar os problemas que as professoras elencaram desde o momento em que aceitaram integrar a equipe e se predispuseram a enfrentá-los. Nesse sentido, estamos diante de uma pesquisa qualitativa, participante, mobilizadora e militante.

Tanto em São Paulo como nos dois outros polos, os interesses do projeto e o das três escolas parceiras convergiam para o "desafio" de construir um novo programa para o Fundamental de nove anos. Na EA-FEUSP, esse desafio coletivo facilitou consensos e permitiu uma boa mobilização para manter os quatro anos de trabalho, embora, podemos afirmar que o primeiro ano do projeto, apesar da boa convivência com o grupo, não foi suficiente para que as professoras assumissem os principais conceitos trazidos pelo grupo. Na EA-FEUSP, as professoras são bem formadas, recebem influências também de outros pesquisadores da Universidade, então, sabíamos que iríamos contar com constantes e renitentes confrontos de ideias e de posturas, contudo estávamos preparados para coordenar debates polêmicos, mas bem profícuos, pois todos sabemos, quando os professores assumem seus programas, sustentam-nos com convicção. As mudanças no currículo ou nas estratégias e no modo de organizar o trabalho estão sempre sujeitas a complexas negociações, com obrigatórias concessões de ambas as partes. Como boas leitoras, as educadoras conheciam boa parte desse estado da arte da alfabetização e da leitura mencionado no início desse texto e desenvolviam uma prática alicerçada tanto pelas influências dos documentos oficiais e programas governamentais federais (PCN, PNLD, SAEB, PNAIC e outros) como nos propostos pelas redes estaduais e municipais de ensino (exemplos, SARESP, LER E ESCREVER e outros), cujo ponto comum se estabelece em torno de uma concepção de língua, linguagem e escrita que implicam a ideia de cidadania e de um letramento cuja função seria subsidiar a participação e a integração social do aluno.

Desde as primeiras discussões encetadas em 2010, quando ainda estávamos elaborando o projeto Desafio, um confronto foi se delineando em torno do modo de se considerar a infância, sobretudo na tensão entre as possibilidades do conhecimento a partir de certo espontaneísmo inerente à infância (o brincar, o ludismo infantil) e o recorte de objetivos claros exigíveis para as séries iniciais do EF-I em um planejamento escolar que tomasse o ensino a partir da concepção de ciclos. 
As professoras organizavam seus programas a partir da concepção de gêneros do discurso exposta nos PCN II (BRASIL, 1998), que tem como fundamentação teórica geral o artigo de Bakhtin (2000) "Gêneros do Discurso" relido por Bronckart (1999), Schnewly (2004) e por diversos autores brasileiros, conforme já dito no início deste texto. Essa concepção de gênero, no EF-I e até mesmo na Educação Infantil (EI), era assumida juntamente com outras influências teóricas advindas da Psicologia - o construtivismo de Ferreiro e Teberosky (1989); da Linguística - (conceitos de variação linguística, de língua enquanto uso); da Educação (conceitos de letramento e de infância relacionado ao "brincar" etc.). Todas essas influências e até mesmo outras não citadas aqui punham em jogo uma prática que, na opinião dos coordenadores e dos pósgraduandos do projeto, contribuía para resultados não tão auspiciosos no final do ciclo segundo as próprias professoras da EA-FEUSP os resultados no final de ciclo não eram nada satisfatórios, pois, no quinto ano detectava-se sempre um número razoável de alunos com sérias dificuldades tanto na leitura como na escrita. Da transposição pedagógica da teoria dos gêneros do discurso, o programa da escola tomava como referência a estratégia de assumir um gênero principal em cada ano (o primeiro e o segundo, por exemplo, ficaram respectivamente com "contos de fada" e "fábulas") e uma certa diversidade de gêneros, cujos textos seguiam a orientação de contemplar o universo de letramento da criança (logomarcas, propagandas, rótulos, receitas, bilhetes, textos de jornais e revistas e outros) e, claramente, a ideia de usos da língua e reconhecimento da função social da escrita, tópicos muito apregoados por diversos educadores brasileiros nas três últimas décadas.

Em Belintane (2013), despendemos todo o capítulo II para analisar esse cruzamento de teorias e evidenciar que essa dispersão de gêneros e de tipos textuais está presente nos programas do Ministério da Educação e nos documentos e avaliações das redes estaduais e municipais de ensino, bem como nos livros didáticos selecionados pelo Programa Nacional do Livro Didático - PNLD (BRASIL, 1998). Como tais teorias vieram se gestando na segunda metade do século passado e impactando o ensino desde a década de oitenta (MARINHO, 1998) e o entrecruzamento delas não chegou a ser razoavelmente analisado, o resultado tem sido bem caótico (BELINTANE, 2013; BATTAGLIA, 2013; NANCI, 2013; BORTOLACI, 2015; JOAQUIM, 2016). Na EAFEUSP, graças ao bom nível das professoras, o efeito não chegou a ser tão deletério, como o que se constata em escolas públicas brasileiras (BELINTANE, 2013). Sabemos bem que as influências dessas teorias necessitam de um reposicionamento, sobretudo 
em relação às transposições que se fazem para a EI e anos iniciais do EF-I. Vejamos alguns exemplos desses reposicionamentos: (1) enfatizamos ao grupo que o conceito de cidadania (sempre requerido pela Educação hodierna) quando aplicado à criança não pode ser o mesmo que se aplica ao mundo adulto; (2) os gêneros e textos que podem potencializar o letramento e alfabetização não dependem necessariamente do ambiente próximo (pretenso universo de letramento) e nem sempre são os que circulam hoje, pois em geral estão ligados às fantasias da infância - os que verdadeiramente entusiasmam e encantam as crianças, a ponto de desejarem assumir o posicionamento de leitor, não sãos os textos e fatos prosaicos do cotidiano (ORTEGA Y GASSET, 1993; BELINTANE, 2013); (3) contemplar a diversidade de gêneros textuais ou mesmo discursivos como preceituam os PCN e boa parte dos autores herdeiros da escola de Genebra pode ser consentâneo a criar uma dispersão e isso não vai bem com a infância, que precisa da repetição de padrões - uma criança de seis anos ainda pede para contar a mesma história várias vezes; (4) Oralidade, para nós, é diferente de fala prosaica - contemplar a fala cotidiana pode até ser interessante do ponto de vista dos Sociolinguistas, da Linguística, de uma certa Pragmática e da Educação em geral, mas no processo de alfabetização resulta em estratégias pouco eficazes, pois o pareamento mais adequado para a criança ou mesmo adulto entrar na leitura e na escrita não se dá apenas com a fala cotidiana, mas sim com gêneros e textos que põem em relevo a função poética e narrativa (BELINTANE, 2016, no prelo; JOAQUIM, 2016).

Passamos boa parte do período letivo de 2011 discutindo essas diferenças e analisando a prática cotidiana da escola em nossas reuniões. Ao longo dos demais anos (até o final de 2014 e parte de 2015), as discussões foram se consolidando sempre tendo como contexto aplicado às turmas que ingressaram em 2011 e 2012. Em nossa metodologia, as turmas de 2011 funcionavam como "reflexo", ou seja, as professoras participavam do grupo, recebiam orientações, mas não estavam no foco em termos de intervenções e mudanças curriculares, a presença dessas turmas era importante para balizar as ações que se aplicavam nas turmas de 2012, que eram as turmas-foco, as que de fato sofreram as intervenções mais significativas a tal ponto de chegarmos em 2015 a um documento para a reformulação do currículo de Língua Portuguesa (BELINTANE, 2015).

Abaixo, descreveremos os pontos mais importantes das reflexões, reformulações e intervenções realizadas ao longo de todo o processo - de forma sintética em razão dos limites de página. 


\section{Consolidação da equipe para enfrentar os desafios do regime de ciclo}

O modelo de atuação do projeto de alguma forma previa também em sua progressão anual as "dobradiças de entre-anos e de entre-ciclos" - o esquema abaixo ilustra o modelo do Fundamental I e suas articulações com a Educação Infantil e com o Fundamental II ( $6^{\circ}$ ano):

Figura 1 - Ciclos e dobradiças

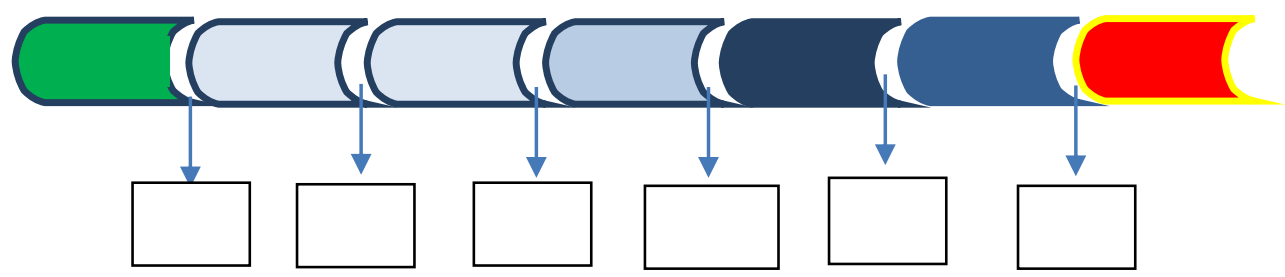

Legenda: DC : Dobradiça de Entre-Ciclos; DA : Dobradiça de Entre-Anos

Fonte: Elaboração própria.

Como a EA-FEUSP não tem turmas de Educação Infantil (aba verde, EI), a dobradiça (DC1) foi feita a partir da análise dos portfólios das crianças egressas das diversas escolas infantis (aqui já temos uma primeira exigência do regime de ciclos, iniciar o fundamental I, conhecendo os portfólios de cada criança, não fazer tabula rasa de sua escolarização anterior!). Os resultados dos diversos portfólios recolhidos passaram a constituir um arquivo de documentos para professores, pesquisadores e estagiários, que tomaram o tema como uma demanda emergente para a FEUSP e para a escola pública em geral.

Essas dobradiças consistiam em uma série de interações programadas ou emergentes ao longo do ano, nas quais as professoras conheciam a heterogeneidade das turmas e as estratégias de que lançavam mão sobretudo para lidar com os casos mais complexos - alunos que, desde o início do ano, apresentavam dificuldades para, no campo da Oralidade, ouvir e recontar histórias, memorizar pequenos textos lúdicos etc. e, no da Leitura, para reconhecer letras e entender suas funções, ler imagens, decifrar rébus, palavra-valises ${ }^{2}$ etc.). Como já experimentado no projeto, as dobradiças implicam uma série de interações entre professores e até possíveis lidas com re-agrumentos de turmas ao longo do ano e no seu final, de tal modo que, na passagem de uma série a

${ }^{2}$ Esses itens curriculares estão descritos detalhadamente em Belintane (2013). 
outra, ficassem garantidos um amplo conhecimento sobre a situação de cada aluno e um conjunto de estratégias que contemplassem as defasagens de nível de todas as turmas implicadas. Levando em conta os ciclos da EA, teríamos a primeira dobradiça DC1 no primeiro ano, depois a DA1 (entre primeiro e segundo) e na sequência, a DA2 (primeiro e terceiro) e outra de ciclo, DC3 (entre terceiro e quarto anos). De DC1 a DC3, os objetivos e consolidações do programa tornaram-se bem claros. Nesse contexto, as capacidades de avaliar, diagnosticar, escutar os alunos, discernir diferenças constituíam o eixo qualitativo da pesquisa e do trabalho que se implementava com as professoras. Avaliações, diagnósticos e análises de seus dados forneciam a base para as intervenções programáticas e busca de novas estratégias, sobretudo para lidar com as defasagens.

A atribuição de aula/de turmas em cada ano deveria levar em conta a consolidação dessa experiência e não seguir apenas a ideia de que os professores simplesmente tenham que se diversificar em suas atuações. Experiências bem consolidadas em cada dobradiça ajudam a constituir uma equipe de trabalho com consciência e domínio do fluxo ao longo dos anos e ciclos. Um regime de ciclo exige uma equipe bem articulada. Seria muito interessante que o grupo de cada ciclo fosse se especializando, estudando cada vez mais as questões principais de suas dobradiças (ingresso e egresso). Infelizmente neste ponto não fomos ouvidos, a atribuição das turmas continua sendo feita a partir de outros critérios, apesar de termos constatado a permanência de professoras que estão se tornando pesquisadoras da heterogeneidade.

A partir de 2012, o trabalho em equipe se efetivou, as professoras começaram a atuar de forma mais solidária. A responsabilidade, antes individualizada, focada na turma, no ano, passou a ser mais extensa (do primeiro ao terceiro). Chegamos a recombinar turmas de acordo com resultados de avaliações e diagnósticos, ou seja, as três turmas do primeiro ano e as duas do segundo, eram reagrupadas momentaneamente (por dez ou quinze aulas) a partir de objetivos não efetivados por este ou aquele grupo, por exemplo: os alunos do primeiro ano que ainda não dominavam a sílaba simples, passaram a constituir um grupo com este objetivo e este grupo poderia receber até mesmo alunos do segundo ano, que estavam na mesma situação. Formamos grupos também para enfrentar desafios, aprender mais, pois estes alunos em geral tinham cumprido todos os objetivos para o ano e a idade. A estratégia do reagrupamento apresentou ótimos rendimentos tanto em São Paulo como em Belém.

O mais relevante dessa experiência é que a ideia de equipe se efetivou de forma diferente do trabalho de sempre. De 2012 em diante, as responsabilidades se tornaram 
mais coletivas, o esforço deixou de ser solitário, mesmo a ideia de formação continuada mudou, pois passou-se a enxergar com mais clareza a necessidade de formações pontuais, por exemplo: aprender a contar história; a praticar leitura em voz alta, reunir acervos de textos orais; preparar materiais didáticos específicos para esta ou aquela dificuldade; diagnosticar oralidade-leitura-escrita e não apenas a partir da escrita; exercer uma escuta mais acurada das singularidades de cada aluno - sobre este último tópico chegamos a elaborar e a partilhar um texto, que será capítulo de livro (BELINTANE, 2016 prelo). Essas experiências foram relatadas com muito sucesso pelas próprias professoras nas aulas de graduação da Pedagogia FEUSP e também as apresentaram em eventos ocorridos nos três polos do projeto (Belém em 2012, Pau dos Ferros, em 2013, São Paulo, em 2014).

O conjunto dessas experiências, incluindo aqui a consciência sobretudo das professoras que atuaram do primeiro ao quinto ano (com exceção de uma delas, que teve uma participação mais conflituosa e resolveu sair do grupo) sobre a relevância de nossas intervenções, dão-nos convicção suficiente de que nossa pesquisa participante cumpriu as exigências mais rigorosas dessa modalidade. Contar com o grupo unido, expondo suas experiências em salas de aula da Universidade e em outras universidades (UFPA - Belém; UERN - Pau dos Ferros, incluído aqui o público das escolas parceiras de cada universidade), evidencia e comprova o valor das intervenções para os implicados. Neste sentido, como preconizam Thiolent (2003), autores da coletânea organizada por Brandão (1999) e outros defensores desta modalidade de pesquisa, a relação sujeito-objeto evidenciou-se como dialética, apagando sua armação dicotômica e pondo em relevo uma interação profícua para os pesquisadores e para a escola-campo e suas professoras. Uma das missões (objetivos) do grupo, pactuada em 2010, nas primeiras discussões do projeto, fora posta em ação: recuperar a vocação de uma Escola de Aplicação, cujo objetivo mais nobre, que poderia justificar a razão de sua existência, está na capacidade de pôr seu currículo como referência para as escolas públicas em geral e à disposição de outros pesquisadores da área da educação. Podemos concluir que as condições gerais para isto foram alcançadas e experimentadas em três eventos organizados pelo projeto, em 2012 (UFPA-Belém), 2013 (Pau dos Ferros- UERN) e 2014 (FEUSP-SP), nos quais sete professores dos primeiros, segundos e terceiros anos apresentaram estratégias e resultados. Uma delas tornou-se mestra, sob orientação do coordenador geral da pesquisa, tematizando exatamente o novo currículo da escola (BORTOLACI, 2015). Entretanto, os passos dados deverão ser sustentados com 
autonomia, resta agora à nova direção da EA-FEUSP, o Conselho Escolar e a comunidade em geral organizarem-se para esta tarefa (divulgar seu currículo no site da escola, realizar e participar de eventos, publicar etc.), embora as perspectivas não sejam nada promissoras, pois desde 2015 a nova Reitoria da universidade vem acenando com cortes de verbas e vetos em relação à contratação de novos professores para as vagas resultantes de aposentadorias (neste período, duas professoras do EF-I se aposentaram, sobrecarregando a equipe).

\section{Alterações no programa e articulações curriculares}

A partir de 2012, as professoras do primeiro ano fizeram grandes mudanças em seus programas, deixaram de estruturar o programa exclusivamente a partir da concepção de gênero ("um gênero principal e outros de fundo", como costumavam dizer) e assumiram, ainda que parcialmente, a concepção de oralidade-escrita do projeto). Puseram em primeiro plano a cultura oral brasileira (contos e ludismos orais das diversas regiões brasileiras) e de imediato perceberam que o rendimento era outro, que até mesmo era possível manter a proposta de um programa lúdico para o primeiro ano, mas a partir de tópicos avaliáveis e com controle da aprendizagem. Outra perspectiva curricular que se efetivou foi a ideia de identificar a infância com o que chamávamos "palavra esperta" ou mais precisamente "função poética" e conceber a entrada na escrita em paralelo e articulada com a oralidade formular - o programa passou a distinguir nosso conceito de oralidade do uso prosaico da língua (interação espontânea com os alunos, roda de conversa e outras modalidades de uso da língua que costumavam praticar). Para nós, oralidade se refere a processos de textualização oriundos da cultura oral, que lançam mão de recursos estéticos (ritmo, métrica, rima, paralelismos e outros elementos da função poética, além da função narrativa). A escolha do texto passou a levar em conta outros elementos que não apenas o gênero: tamanho do texto (fizemos questão de que os alunos lidassem também com textos de maior volume, tanto orais como escritos), sua origem (se da oralidade tradicional ou da escrita), a qualidade estética da textualização e outros. No segundo ano de 2013, essas mesmas turmas "deram a volta ao mundo" a partir de contos de diversas regiões do planeta - as professoras fizeram uma bela interdisciplinaridade da literatura de origem oral com geografia e história, matemática e ciências. 
Também enfrentamos um desafio a que os professores não estavam habituados em razão da influência construtivista: lidar com os elementos menores do código (letras, fonemas, sílabas, dígrafos, rébus etc.), mas não na mesma perspectiva de Soares (2016) ou mesmo das metodologias fônicas e silábicas, já que nossa referência não se dá por meio de um pareamento direto entre fala cotidiana e escrita, mas sim entre a oralidade formular (HAVELOCK, 1996), a poesia, os elementos principais da narrativa e o ato de ler e de escrever. Para nós, a oralidade (que também chamamos corporalidade) é uma ferramenta preciosa, da qual os gregos lançaram mão para assimilar o alfabeto fenício e a partir desse entrecruzamento, sistematizaram o alfabeto tal como o conhecemos (criaram a noção de consoante ao inventarem símbolos para as vogais - com esse feito, tem início de fato a escrita ocidental com o algoritmo silábico consoante-vogal). Tomamos como hipótese e a confirmamos que para inventar (ou entrar em) uma escrita alfabética é preciso ter uma oralidade forte, ou seja, uma memória com matrizes textuais de gêneros que de fato coloquem em relevo uma estética mnemônica. Nesta perspectiva, a leitura não nasce do pareamento com a fala - deste jogo nasceria no máximo um uso funcional do alfabeto - mas sim do compromisso e do posicionamento subjetivo da criança diante de uma estética mnemônica e literária capaz de enlaçar o entusiasmo infantil. Por isso muitas de nossas estratégias foram extraídas da própria história da escrita: o uso do rébus, da acrofonia, da homofonia, da imagem, da palavra valise e dos ludismos orais para ajudar a criança a dar conta da sílaba oral e escrita (NANCI, 2013).

Conforme mostraram as professoras em suas falas e relatórios, o resultado foi bem diferente dos outros anos, o número de alunos que terminou o primeiro ano lendo foi bem maior. De fato, o desempenho desses alunos na Provinha Brasil mostrou isso, como se verá adiante. Para resumir, o esquema do programa para a consolidação do currículo estabelece um jogo dinâmico entre atividades ligadas à corporalidade (gêneros oriundos da tradição oral, brincadeiras com elementos menores do código a partir de estratégias e conceitos extraídos da história da escrita e da poética), à imagem, considerando seu dinamismo digital (transição oralidade-escrita a partir de imagens associadas à escrita) e à atividades de leitura e escrita, conforme a Tabela 1: 
Tabela 1 - Esquema do programa para a consolidação do currículo

\begin{tabular}{|c|c|c|}
\hline Coluna 1 & Coluna 2 & Coluna 3 \\
\hline CORPORALIDADE & $\begin{array}{c}\text { TRANSIÇÃO } \\
\text { ORALIDADE- } \\
\text { ESCRITA }\end{array}$ & AEITURA/ESCRITA \\
\hline Acrofonia oral & $\begin{array}{c}\text { Acrofonia oral } \\
\text { Partir de imagens }\end{array}$ & Acrofonia a partir da \\
\hline Palavra-valise oral & $\begin{array}{c}\text { Palavra-valise } \\
\text { oral a partir de imagens }\end{array}$ & Palavra-valise a partir \\
da escrita
\end{tabular}

Fonte: Elaboração própria.

Na coluna 1 prevalecem atividades essencialmente performáticas; na dois, as atividades são subsidiadas por imagens (os alunos são instados a relacionar a imagem com o respectivo nome ou mesmo a lerem a imagem até identificá-la como trechos de um conto), na três, as atividades dominantes são as de escrita. Exemplificando: podemos tomar um conjunto de palavra extraído de um conto já escutado antes (menino, coca, avó, angu, parede, lavadeira, cesteiro etc. - palavras extraídas da "História da coca"), a criança deverá tomar três ou quatro de cada vez e repetir rapidamente apenas sua sílaba inicial - as quatro grifadas seriam repedidas assim: me, co, a, na. Em seguida, o aluno faz isso a partir das imagens dessas palavras (ao ver a imagem no PowerPoint ou em figurinha sobre a mesa, nomeia-as apenas com a sua sílaba inicial (princípio acrofônico), depois retomará essas mesmas atividades na escrita (terceira coluna)). Tudo isso se dá de forma bastante lúdica e animada.

Este esboço inicial permitiu também um planejamento que se expandiu ano a ano. Como já dito, o resultado deste trabalho está presente na dissertação de mestrado de Bortolaci (2015).

A consolidação progressiva deste programa, feita ano a ano, continua na EAFEUSP, sendo orientadas pelo coordenador do projeto. 


\section{Acompanhamento longitudinal e seus resultados}

O acompanhamento de todos os alunos, sobretudo daqueles que apresentam defasagem ao longo do ano e dos ciclos é um dos compromissos fundamentais da construção do currículo organizado em ciclos prometido às professoras. A lida com a heterogeneidade passou a ser cotidiana e a integrar a própria dinâmica das turmas, não era mais relegada aos períodos de "recuperação". As dificuldades do manejo cotidiano dos agrupamentos de alunos ou mesmo o atendimento individualizado a esta ou aquela criança levou-nos a confirmar uma hipótese que já trazíamos desde o projeto anterior: não é possível praticar o regime de ciclo, garantindo o direito de aprendizagem de todos os alunos, mantendo apenas um professor por turma. Na EA, a atuação dos bolsistas foi crucial para que todos os alunos pudessem ser acompanhados e essas intervenções nos mostraram que a alfabetização e o ensino das bases da matemática exigem intenso trabalho em equipe, de preferência com professores de diversas áreas (letras, linguística, pedagogia e outras) em uma proporção de ao menos $3 p$ x $2 t$, ou seja, para cada duas turmas, um profissional a mais. Na EA esse profissional passou a existir a partir de 2013 com o nome de "professor de ciclo", cuja função era basicamente a lida com a heterogeneidade.

Para finalizar, apresentaremos os resultados gerais deste acompanhamento seguidos dos comentários finais.

Dos sessenta alunos ingressantes em 2012, vinte e cinco alunos necessitaram de acompanhamento. Aparentemente é um número razoavelmente alto, 41\%, contudo, muitos deles foram acompanhados em dificuldades pontuais, mas muitas vezes cruciais. Diante da constatação no final do ciclo (quinto) de que três alunos desse grupo que apresentavam dificuldades para compreender o funcionamento da sílaba, cujas situações foram resolvidas rápida e pontualmente já no primeiro ano, figuravam entre os melhores leitores da classe (acertando por volta de 90\% de nossos exigentes testes), isolamos a pergunta: estariam eles nesta situação se não tivessem passado por intervenções pontuais precoces? Se ficassem esperando o "clic" ou o tempo para construírem suas hipóteses sobre a relação língua-escrita teriam o mesmo rendimento? Isso nos mostra que a intervenção já no primeiro ano é fundamental tanto para a criança com dificuldades mais complexas como também para as que apresentam questões mais pontuais. 
Além das avaliações praticadas ordinariamente pelas professoras, a equipe do projeto aplicou diversas avaliações de leitura, recobrindo tópicos que compreendiam amplos aspectos do texto escolhido: compreensão geral do texto e parciais (parágrafos), compreensão de episódios, inferência de palavras desconhecidas, função dos dêiticos etc. Diferentemente das avaliações do SAEB (Provinha Brasil e Prova Brasil) (BRASIL, 2004), do SARESP (BRASIL, [S.d.]) e das avaliações da rede municipal de São Paulo, nossa equipe avalia a compreensão de apenas um texto complexo e relativamente longo (de 1,5 a 2,5 páginas). Na avaliação final aplicada ao quarto ano (alunos que foram acompanhados desde 2012), realizada no final de 2015, obtivemos os seguintes resultados da turma em geral (prova tipo teste, com 15 questões de múltipla escolha, do tipo 1 correta para 3 distratores):

Tabela 2 - tabela da avaliação final do projeto

\begin{tabular}{|c|c|c|c|c|c|}
\hline Níveis & Meninos & Meninas & Total & $\%$ & Média \\
\hline De 10 a 15 respostas certas & 15 & 13 & 28 & 46,66 & \multirow[t]{2}{*}{76,33} \\
\hline De 07 a 09 & 09 & 09 & 18 & 30,00 & \\
\hline De 05 a 06 & 01 & 05 & 06 & 10,00 & \multirow[t]{2}{*}{23,33} \\
\hline Abaixo de 5,0 & 06 & 02 & 08 & 13,33 & \\
\hline Total das duas turmas & 30 & 30 & 60 & 100 & 99,66 \\
\hline
\end{tabular}

Fonte: Elaboração própria.

A partir da análise da produção escrita desses sessenta alunos, sobretudo a reescrita de textos ouvidos em roda de leitura em voz alta, podemos afirmar que, com exceção de dois alunos de inclusão, que escrevem frases curtas (iniciaram muito tardiamente o processo e aprendem muito devagar com a ajuda nos atendimentos), notamos que os 58 alunos são capazes de produzir textos, mas há de fato (comprovado no relatório das professoras destas turmas), um grupo (próximo deste percentual de $20 \%$ que ainda possui dificuldades para enfrentar textos mais longos e complexos como o da avaliação que fizemos). Apesar dessa diferença e levando em conta as exigências de nossas avaliações, desempenho próximo a este das turmas de 2002, segundo depoimento das professoras, nunca foi atingido por turmas anteriores.

Na "Provinha Brasil" (BRASIL, 2004) e na ANA - Avaliação Nacional de Alfabetização" (BRASIL, 2015) essas turmas mostraram um excelente rendimento. Vejamos 
Tabela 3 - Provinha Brasil 2013 ( $2^{\circ}$ ano, turmas de 2012)

\begin{tabular}{|l|l|l|}
\hline Níveis & Faixa de acertos & $\%$ \\
\hline Nível 5 & de 19 a 20 acertos & $\mathbf{4 4 , 8 2}$ \\
\hline Nível 4 & de 14 a 18 acertos & $\mathbf{4 8 , 2 7}$ \\
\hline Nível 3 & de 9 a 13 acertos & 06,89 \\
\hline Nível 2 & de 4 a 8 acertos & 00,00 \\
\hline Nível 1 & até 3 acertos & 00,00 \\
\hline
\end{tabular}

Fonte: Elaboração própria.

Tabela 4 - ANA - 2015 (3 . Ano, turmas de 2012)

\begin{tabular}{|l|c|c|}
\hline Níveis & LEITURA & PRODUÇÃO TEXTUAL \\
\hline Nível 5 & & $\mathbf{3 5 , 5 9 \%}$ \\
\hline Nível 4 & $42,37 \%$ & $\mathbf{6 2 , 7 1 \%}$ \\
\hline Nível 3 & $\mathbf{4 2 , 3 7 \%}$ & $\mathbf{1 , 6 9 \%}$ \\
\hline Nível 2 & $\mathbf{1 3 , 5 6 \%}$ & Zero \\
\hline Nível 1 & $\mathbf{1 , 6 9 \%}$ & Zero \\
\hline
\end{tabular}

Obs.: A coluna "LEITURA" é formada por quatro níveis apenas

Fonte: Elaboração própria.

Como se pode ver, tanto em leitura como em produção de texto, tanto em uma prova como em outra, os alunos das turmas de 2012 apresentam rendimentos excelentes. Somando os percentuais dos níveis considerados pelo Ministério da Educação, teríamos: Provinha Brasil/2013 = 93,09\%; ANA/2014/LEITURA: 84,74\%; ANA 2014 PRODUÇÃO DE TEXTOS: 98,03\%. Apesar desse bom desempenho nas provas oficiais, acreditamos que a melhor avaliação de leitura é a que realizamos (Tabela 2), pois esta exige uma visão mais integral do texto e está de acordo com a nossa perspectiva de alfabetização e leitura: um bom leitor tem que ser capaz de ler um texto de boa extensão com nível para a sua idade e da forma mais completa possível - e não apenas pinçar fragmentos e obter o escore final a partir de somas de itens ou de habilidades parcializadas, como se faz nas avaliações do MEC. Nas avaliações da Prova Brasil (BRASIL, 2004) a soma de habilidades isoladas compõe o nível de leitura, em nossas avalições a soma dos acertos nos testes revela habilidades que co-ocorrrem em um mesmo processo de leitura, em um mesmo texto, por isso o desempenho de cada 
aluno é cotejada à respectiva produção de textos e a uma análise mais minuciosa das opções pelas alternativas erradas (análise dos distratores) - uma análise mais qualitativa (essa análise está minuciosamente elaborada em Belintane (2016, no prelo)).

Os dados ainda serão analisados mais detalhadamente, mas o que salta à vista desde já é que o monitoramento das turmas associado a um currículo que valorize a relação oralidade escrita tal como acima evidenciado, não resultam em uma turma homogênea, pois as diferenças tendem a se manter, mas melhora significativamente o nível de leitura.

\section{REFERÊNCIAS}

BAKHTIN, M. Os gêneros do discurso. Estética da Criação Verbal. 3.ed. São Paulo: Martins Fontes, 2000.

BATTAGLIA, L. Das memórias narrativas às representações mítica: arte e desafios na alfabetização. 2013. 449 f. Tese (Doutorado em Linguagem e Educação) - Faculdade de Educação, Universidade de São Paulo, São Paulo, 2013.

BELINTANE, C. Da corporalidade lúdica à leitura significativa: subsídios para a formação de professores. 2016. No prelo.

BELINTANE, C. Oralidade, alfabetização e leitura: enfrentando diferenças e complexidades na escola pública. Educação e Pesquisa, São Paulo, v.36, n.3, p.685$703,2010$.

BELINTANE, C. Oralidade e alfabetização: uma nova perspectiva da alfabetização o e do letramento. 1.ed. São Paulo: Cortez Editora, 2013.

BElintane, C. Contribuições do Projeto desafio ao Currículo de Língua Portuguesa da Escola de Aplicação da FEUSP. [S.1.]: GOLE - Grupo Oralidade Leitura e $\quad$ Escrita, 2015. 2 Disponível em: <http://media.wix.com/ugd/59d572_9083d38be0364f4785a72a07d0cf7e43.pdf〉. Acesso em: 13 dez. 2016.

BORTOLACCI, N. Alfabetização no ensino fundamental: novas bases curriculares. 2015. 158 f. Dissertação (Mestrado em Educação) - Faculdade de Educação, Universidade de São Paulo, São Paulo, 2015.

BRANDÃO, C. (Org.) Repensando a pesquisa participante. São Paulo: Brasiliense, 1999.

BRASIL. INEP - Instituto Nacional de Estudos e Pesquisas Educacionais Anísio Teixeira. ANA - Avaliação Nacional da Educação. Brasília: INEP, 2015. 
BRASIL. Ministério da Educação e do Desporto. Parâmetros Curriculares Nacionais Ensino Fundamental $\left(5^{\mathbf{a}}\right.$ a 8 $)$. Brasília: MEC/SEF, 1998.

BRASIL. (SAEB). Resultados do SAEB/2003. Junho de 2004 (versão preliminar). Brasília: INEP, 2004. Disponível em: <http://www.inep.gov.br/basica/saeb/default.asp>. Acesso em: 13 out. 2015.

BRASIL. SARESP - Sistema de Avaliação do Rendimento Escolar do Estado de São Paulo. Brasília: Secretaria da Educação, [S.d]. Disponível em: <http://www.educacao.sp.gov.br/saresp>. Acesso em: 13 dez. 2016.

BRONCKART, J. P. Atividades de linguagem, textos e discursos: por um interacionismo sócio-discursivo. São Paulo: EDUC, 1999.

FERREIRO, E.; TEBEROSKY, A. Los sistemas de escritura en el desarrollo del niño. 11.ed. México: Editora Siglo XXI, 1989.

HAVELOCK, E. A musa aprende a escrever: reflexões sobre a oralidade e a literacia da antiguidade ao presente. Lisboa: Gradiva, 1996.

JOAQUIM, I. R. A criança entre a voz do verso e a letra do sentido: a poesia no processo de alfabetização. 2016. 263 f. Dissertação (Mestrado em Educação) Faculdade de Educação, Universidade de São Paulo, 2016.

MARINHO, M. A língua portuguesa nos currículos de final de século. In: BARRETO, E. S. S. (Org.). Os currículos do ensino fundamental para as escolas brasileiras. Campinas: Autores Associados, 1998. p.43-90.

NANCI, K. Narrativas que evocam, memórias e subjetividades. 2013. 190 f. Dissertação (Mestrado em Linguagem e Educação) - Faculdade de Educação, Universidade de São Paulo, 2013. Disponível em <http://media.wix.com/ugd/59d572_95f9f1e8abe748dfa67ef622dc823bc1.pdf>. Acesso em: 13 dez. 2016.

ORTEGA y GASSET, J. El Quijote en la escuela. Revista da Faculdade de Educação, São Paulo, v.19, n.1, 1993.

SCHMIDT, M. L. S. Pesquisa participante: alteridade e comunidades interpretativas. Psicologia USP, São Paulo, v.19, n.2, p.11-41, 2006.

SCHNEUWLY, B. et al. Gêneros orais e escritos na escola. Organização e Tradução de R. H. R. Rojo e G. S. Cordeiro. Campinas: Mercado de Letras, 2004.

SOARES, M. Alfabetização: a questão do método. São Paulo: Contexto, 2016

THIOLLENT, Michel. Metodologia da pesquisa-ação. 12.ed. São Paulo: Cortez, 2003. 


\section{Como referenciar este artigo}

BELINTANE, Claudemir. O desfio do ensino da leitura no contexto contemporâneo. Revista Ibero-Americana de Estudos em Educação, Araraquara, v.11, n. esp. 4, p. 23612379, 2016. Disponível em: <http://dx.doi.org/10.21723/riaee.v11.n.esp4.9198>. EISSN: 1982-5587.

Submetido em: setembro/2016

Aprovado em: outubro/2016 